\title{
Type 2 proatlantal intersegmental artery
}

\author{
Akira Uchino $^{1}$ (1) \\ Received: 17 November 2017 / Accepted: 5 December 2017 / Published online: 8 December 2017 \\ ○) Springer-Verlag France SAS, part of Springer Nature 2017
}

\section{Dear Sir,}

I read with great interest the recent article titled "The right vertebral artery originating from the right occipital artery and the absence of the transverse foramen: a rare anatomical variation" by Öner et al. [1] published in Surgical and Radiologic Anatomy (2017;39:1397-1400). The proatlantal intersegmental artery (PIA) enters into the posterior fossa via the foramen magnum, and comprises two types; type 1 arises from the internal carotid artery and type 2, from the external carotid artery (ECA). The type 2 PIA is an extremely rare congenital anastomosis between the proximal ECA and vertebral artery. Reviewing Figure 7, I believe that this patient has type 2 PIA. Because, this anastomotic artery between the ECA and the vertebrobasilar system runs in the similar course of our patient previously reported [2]. In our patient, the distal branch of the occipital artery arose from the anastomotic artery. Thus, the proximal segment of the anastomotic artery was regarded as a dilated occipital artery. This type of congenital anastomosis between the occipital artery and the vertebral artery via the foramen magnum is called as a type 2 PIA or persistent first cervical intersegmental artery [3].

\section{Compliance with ethical standards}

Conflict of interest The author declares no conflict of interest.

\section{References}

1. Öner Z, Öner S, Kahraman AS (2017) The right vertebral artery originating from the right occipital artery and the absence of the transverse foramen: a rare anatomical variation. Surg Radiol Anat 39:1397-1400

2. Uchino A, Saito N, Inoue K (2012) Type 2 proatlantal intersegmental artery associated with persistent trigeminal artery diagnosed by MR angiography. Surg Radiol Anat 34:773-776

3. Uchino A, Saito N, Kurita H (2017) Anastomosis of the external carotid artery and the V3 segment of the vertebral artery (presumed persistent second cervical intersegmental artery) diagnosed by CT angiography. Surg Radiol Anat. https://doi.org/10.1007/ s00276-017-1906-z (Published online: 01 August 2017)
Akira Uchino

auchino@saitama-med.ac.jp

1

\footnotetext{
Department of Diagnostic Radiology, Saitama Medical University International Medical Center, 1397-1 Yamane, Hidaka, Saitama 350-1298, Japan
} 